\title{
Lymphatic Filariasis in Brazilian Urban Area (Maceió, Alagoas)
}

\section{Gilberto Fontes $/{ }^{+}$, Eliana MM Rocha, Ana C Brito, Carlos Mauricio F Antunes*}

\author{
Departamento de Patologia, Centro de Ciências Biológicas, Universidade Federal de Alagoas, Praça Afrânio \\ Jorge s/nํㅡ, 57010-020 Maceió, AL, Brasil *Departamento de Parasitologia, Instituto de Ciências Biológicas, \\ Universidade Federal de Minas Gerais, Caixa Postal 486, 31270-901 Belo Horizonte, MG, Brasil
}

A cross-sectional survey conducted among evening students was used to determine the prevalence of Wuchereria bancrofti infection in Maceió, capital of the State of Alagoas, northeast Brazil. A single thick-blood smear was used, being collected between 10 p.m. and 12 a.m. From a total of 29,551 students enrolled at evening elementary schools in the 33 city sectors, 16,569 (56.4\%) were random selected for inclusion in the study. From those, 10,857 (65.5\%) were interviewed and examined and 73 $(0.7 \%)$ were found to have microfilaraemia. Autochthonous W. bancrofti carriers live in 10 of the 33 city sectors, suggesting a focal distribution. Moreover, $84 \%$ of infections were diagnosed among $29 \%$ of all students examined, inhabiting three contiguous sectors at the city central area, presenting infection rates up to $5.3 \%$. Students living in city sectors with prevalence of microfilariae carriers greater than $1 \%$ were found to have a higher risk for infection when compared to students from the rest of the town [Relative Odds (RO) 12.8, 95\% CI 6.7 - 25.1]. Eleven positive individuals from non endemic areas were living in Maceió for more than 10 years; time of residence in the area was a major risk factor for infection among students not born in the region $(p<0.01)$. Regarding sex, male students presented a higher proportion of positive (RO 1.7, 95\% CI 1.1 - 2.9).

Key words: Wuchereria bancrofti - lymphatic filariasis - epidemiology

Lymphatic filariasis is a severe and impairing disease, with serious social and economical impact. It is endemic in several tropical regions, being estimated that 800 million people live in transmission areas and at least 120 million persons are infected in the world (WHO 1994, Ottesen \& Ramachandran 1995). The etiological agent in Brazil is the Wuchereria bancrofti (Cobbold, 1877) and was probably introduced into the country from Africa with the slave trade during the colonial period (Orihel 1985).

Between 1951 and 1958 several parasitic and entomological surveys were carried out in Brazil. Autochthonous $W$. bancrofti lymphatic filariasis was detected in Manaus, AM; Belém, PA; São Luis, MA; Recife, PE; Maceió, AL; Salvador and Castro Alves, BA; Florianópolis, Ponta Grossa and Barra de Laguna, SC; and Porto Alegre, RS (Rachou

This investigation received financial support from $\mathrm{CNPq}$ and logistic support from Fundação Nacional de Saúde/ AL, Brazil.

${ }^{+}$Corresponding author. Fax: +55-82-221.2501. E-mail: gf@fapeal.br

Received 23 December 1997

Accepted 25 June 1998
1957, 1960). The highest prevalence rates were found in Belém (9.8\%) and Recife (6.9\%) (Rachou 1960). At that time, in Maceió, the proportion of microfilariae carriers was $0.3 \%$ (Deane et al. 1953). After the measures adopted by the Brazilian Lymphatic Filariasis Control Program, a systematic drop in the prevalence rates could be observed and most of the foci were considered extinct. Until recently, the Ministry of Health considered only Belém and Recife as active transmission sites in Brazil (MS 1985). In Recife, W. bancrofti infection is recognized as an expanding public health problem in its metropolitan area, with the proportion of positive reaching $15 \%$ in some city sectors (Dreyer \& Medeiros 1990, WHO 1992).

In Maceió, the description of three autochthonous W. bancrofti microfilariae carriers (Dreyer et al. 1991) added to the existing high densities of the vector Culex quinquefasciatus mosquito, pointed out the need for an epidemiological re-assessment of the infection in this area, which was the objective of the present investigation.

\section{MATERIALS AND METHODS}

Study area - Maceió (9 24' - 9' 35' S latitude and $35^{\circ} 44^{\prime}-35^{\circ} 56^{\prime} \mathrm{W}$ longitude) is the capital of the State of Alagoas, northeast Brazil. An estimated urban population of 555,421 people live within a $208 \mathrm{~km}^{2}$ area subdivided into 33 city sectors. 
Study population - The participants were identified by random selection, using the cluster sampling technique: $50 \%$ of the 84 evening elementary public schools in the 33 city sectors of Maceió were selected (exception for Jacintinho city sector, with small number of schools serving a large population: the existing eight elementary schools were included in the sample). In each selected school, data on students age, sex, birth place and time of residence in the area were obtained. The students present at the school in the examination evening were enrolled in the investigation. The sample size needed to detect the estimated proportion of microfilariae carriers was based upon results obtained from a pilot survey indicating prevalence of $1 \%(\mathrm{n}=10,752$, accepting a $=0.05$ and considering $15 \%$ as the maximum tolerable error).

Blood examination for microfilariae - The blood was obtained by digital puncture, using disposable lancets. A single thick-blood smear (60$100 \mu \mathrm{l})$ was prepared without the use of anticoagulants to avoid the loss of the microfilariae, estimated to reach up to $69 \%$ when these products are employed (Partono \& Idris 1977). The collection was carried out between 10 p.m. and 12 a.m. because of the parasite's nocturnal periodicity in the region (Rocha et al. 1991). Smears were air dried overnight, dehaemoglobinized, fixed with methyl alcohol, stained with eosin-Giemsa and examined for microfilariae. All positive and random selected $33 \%$ of the negative slides were re-examined as quality control. All microfilariae carriers were treated with diethylcarbamazine (WHO 1987) and are being periodically followed at the Tropical Diseases Clinic of the Universidade Federal de Alagoas.

Data analysis - The data was analyzed using the statistical and epidemiological package EPIINFO version 6.02 (Centers for Disease Control and Prevention. Atlanta, GA, USA). The $\mathrm{c}^{2}$ and the $t$ tests were used for comparing proportions and means, respectively; risks were estimated by the relative odds (RO).

\section{RESULTS}

From the 29,551 students enrolled at Maceió's evening elementary public schools, 16,659 (56.4\%) were selected for inclusion in the study; among those, 10,857 students present at the school in the survey evening, who volunteered for participation, were included in the study and examined (from August 1992 to August 1995). The age of the students included in the study ranged from 10 to 56 years, with a mean \pm standard deviation of $18.4 \pm 4.6$ years $(97 \%$ of the sample were $<30$ years old). The mean age of the 5,802 students from whom blood was not collected was $18.4 \pm 4.1$ years; the difference in age between those examined and not examined was not significant. Male students comprised $43.3 \%$ of the those examined; among the students not examined, this proportion was $44.8 \%$. The difference was not significant. The proportion of refusals to participate in the investigation was negligible $(0.3 \%)$.

Seventy-three students $(0.7 \%)$ were found to be infected by $W$. bancrofti. Of the 73 infections all but one was considered autochthonous.

All autochthonous microfilariae carriers reported to be living in ten $(30.3 \%)$ of the city sectors investigated (Table I). Sixty-one (84\%) of the infected participants were identified among 3,122 (29\%) students examined who lived in three central and contiguous city sectors, presenting the following proportion of positive: Feitosa, 5.3\%; Pitanguinha, 3.5\%; Jacintinho, 1.2\%. This finding suggests a focal distribution of this parasitic infection in Maceió (Fig.). Eight other positive students were identified in five city sectors adjacent to those with the highest prevalence of positive; three positive volunteers, identified at peripherical city sectors reported to have lived in the endemic city area. The last case was not considered autochthonous; this person had migrated from other state, also with active foci of transmission and was living in Maceió for less than seven months, time inferior to the usual prepatent period for $W$. bancrofti. It should be pointed out that the prevalence of microfilariae carriers in the city sectors other than the three located at the city central area was always $£ 1 \%$.

Among the positive students, age ranged from 13 to 37 years, with mean $18.1 \pm 4.4$; among the negative, the mean was $18.3 \pm 4.6$ years. The age difference between positive and negative participants was not statistically significant at 0.05 level.

Considering the tested students, the proportion of $W$. bancrofti infection among male and female was $0.9 \%$ and $0.5 \%$, respectively. Taking in account only the students living in the three central city sectors, the proportion of positive among male students $(2.2 \%)$ was higher than that of the female students $(1.3 \%)$, with a RO $=1.7(95 \%$ CI 1.1 2.9).

Students living in city sectors with higher prevalence of microfilariae carriers were found to have a much greater risk of infection when compared to students living in city sectors with infection rates equal or less than $1 \%$ (reference). The overall RO of being infected was $12.8(95 \% \mathrm{CI}$ 6.7-25.1) and was 36.1 (95\% CI 17.2-77.0), 23.7 (95\% CI 7.8-68.9) and 8.1 (95\% CI 4.0-16.7) for Feitosa, Pitanguinha and Jacintinho, respectively (Table II). 


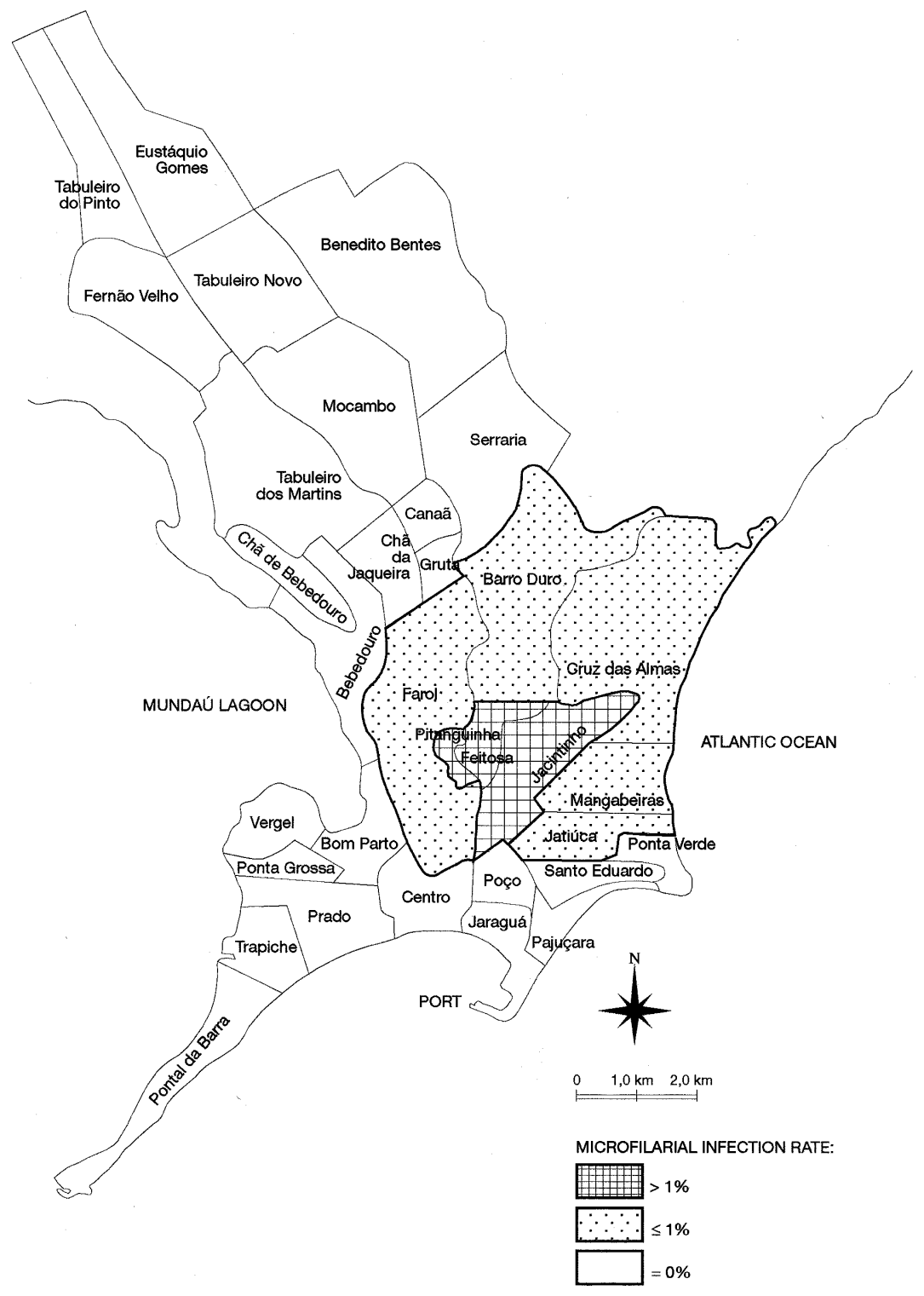

Percent of Wuchereria bancrofti autochthonous microfilaraemic in the 33 city sectors of Maceió, State of Alagoas, Brazil.

Among the 73 infected students, $61(83.6 \%)$ were born and raised in Maceió; 8 (10.9\%) had migrated from other areas within Alagoas and 4 $(5.5 \%)$ from other Brazilian states. One of those had migrated from Recife, an endemic area for $W$. bancrofti and three from states where this parasitic infection is absent. The student from Recife was not considered to be an autochthonous infection, as explained above. The other 11 students were living in Maceió, at the city sectors with higher proportion of positive, for more than 10 years. Comparing infected and non-infected migrants, the mean time of residence in Maceió was significantly greater among the infected (Table III).

\section{DISCUSSION}

This investigation tested, for W. bancrofti infection, $36.7 \%(10,857)$ of all Maceió's evening public school students. Although participation was on a volunteer basis and only those students attending the school in the survey evening were included in the study, there is no evidence of any bias being introduced regarding the sample representativeness. Comparison between examined and not-examined students (age and sex) did not reveal any difference; no evidence was found linking school absence to $W$. bancrofti positivity. Evening students were chosen as the study popu- 


\section{TABLE I}

Number and percentage of Wuchereria bancrofti microfilaraemic students in Maceió, Alagoas (1995), by city sector

\begin{tabular}{|c|c|c|c|}
\hline City sector & $\begin{array}{l}\text { Enrolled } \\
\text { students }^{a}\end{array}$ & $\begin{array}{l}\text { Examined } \\
\text { students }(\%)\end{array}$ & $\begin{array}{l}\text { No. of } \\
\text { positives }(\%)\end{array}$ \\
\hline 1.Feitosa & 966 & 452 (46.8) & $24 \quad(5.3)$ \\
\hline 2.Pitanguinha & 391 & 169 (43.2) & $6(3.5)$ \\
\hline 3.Jacintinho & 5,363 & $2,501 \quad(46.6)$ & $31 \quad(1.2)$ \\
\hline 4.Barro Duro & 493 & 195 (39.6) & $2(1.0)$ \\
\hline 5.Mangabeiras/6.Jatiuca & 2,525 & $591 \quad(23.4)$ & $4 \quad(0.7)$ \\
\hline 7.Eustáquio Gomes & 381 & $140 \quad(36.7)$ & $1 \quad(0.7)$ \\
\hline 8.Cruz das Almas & 482 & $209 \quad(43.4)$ & $1 \quad(0.5)$ \\
\hline 9.Benedito Bentes & 2,020 & $532 \quad(26.3)$ & $2(0.4)$ \\
\hline 10.Farol & 1,011 & $301 \quad(29.8)$ & $1 \quad(0.3)$ \\
\hline 11.Prado & 853 & 377 (44.2) & $1^{b}(0.3)$ \\
\hline 12.Bebedouro & 867 & 366 (42.2) & $0 \quad(-)$ \\
\hline 13.Bom Parto & 610 & $128 \quad(21.0)$ & $0 \quad(-)$ \\
\hline 14.Chã de Bebedouro & 598 & 264 (44.1) & $0 \quad(-)$ \\
\hline 15.Chã da Jaqueira & 1,540 & 633 (41.1) & $(-)$ \\
\hline 16.Canaã/17.Gruta & 320 & 139 (43.4) & $0 \quad(-)$ \\
\hline 18.Fernão Velho/19.Tabuleiro Novo & 1,451 & $599(41.3)$ & $(-)$ \\
\hline 20.Pajuçara/21.Jaraguá & 377 & $272(72.1)$ & $(-)$ \\
\hline 22.Ponta Verde/23.Santo Eduardo & 432 & $189(43.8)$ & $0 \quad(-)$ \\
\hline 24.Poço/ 25.Centro & 1,267 & 327 (25.8) & $(-)$ \\
\hline 26.Ponta Grossa & 1,703 & $527 \quad(30.9)$ & $(-)$ \\
\hline 27.Serraria & 553 & $213(38.5)$ & $0 \quad(-)$ \\
\hline 28.Tabuleiro Martins/29.Mocambo & 1,936 & $642 \quad(33.2)$ & $0 \quad(-)$ \\
\hline 30.Trapiche/31.Pontal da Barra & 1,231 & $422 \quad(34.3)$ & $(-)$ \\
\hline 32. Vergel & 1,940 & $575 \quad(29.6)$ & $(-)$ \\
\hline 33.Tabuleiro do Pinto & 241 & $94 \quad(39.0)$ & $(-)$ \\
\hline Total & 29,551 & $10,857 \quad(36.7)$ & $73 \quad(0.7)$ \\
\hline
\end{tabular}

$a$ : source: State of Alagoas Education Department; $b$ : non autochthonous microfilariae carrier.

TABLE II

Relative odds of being Wuchereria bancrofti microfilaraemic by local of residence (city sector)

\begin{tabular}{lrrrr}
\hline City sector & Microfilaraemic $(\%)$ & No. microfilaraemic $(\%)$ & Relative odds (95\% CI) \\
\hline Rest of city ${ }^{a}$ & $12(0.2)$ & $7,723(99.8)$ & 1.0 (reference) \\
Feitosa & $24(5.3)$ & $428(94.7)$ & $36.1(17.1-77.0)$ \\
Pitanguinha & $6(3.5)$ & $163(96.4)$ & $23.7(7.8-68.9)$ \\
Jacintinho & $31(1.2)$ & $2,470(98.8)$ & $8.1(4.0-16.7)$ \\
\hline
\end{tabular}

$a$ : proportion of positive $£ 1.0 \%$.

\section{TABLE III}

Wuchereria bancrofti microfilaraemic students, according to place of birth and time of residence in Maceió,

Alagoas

\begin{tabular}{|c|c|c|c|c|c|}
\hline \multirow[b]{2}{*}{ Place of birth } & \multicolumn{2}{|c|}{ Infected } & \multicolumn{2}{|c|}{ Not infected } & \multirow[b]{2}{*}{$\mathrm{p}^{b}$} \\
\hline & No. $(\%)$ & $\begin{array}{l}\text { Years of } \\
\text { residence }^{a}\end{array}$ & No. $(\%)$ & $\begin{array}{l}\text { Years of } \\
\text { residence }^{a}\end{array}$ & \\
\hline Maceió & $61 \quad(0.9)$ & $17.6 \pm 4.0$ & 6,930 & $17.9 \pm 4.3$ & 0.54 \\
\hline State of Alagoas & $8(0.3)$ & $13.1 \pm 6.2$ & 2,848 & $7.8 \pm 5.6$ & $0.007^{c}$ \\
\hline Other states & $3(0.3)$ & $14.7 \pm 6.6$ & 1,007 & $7.2 \pm 5.1$ & $0.011^{c}$ \\
\hline
\end{tabular}

$a$ : mean $\pm \mathrm{sd} ; b$ : t test; $c$ : difference statistically significant $(\mathrm{p}<0.05)$. 
lation due to (1) relatively higher prevalences of microfilaraemia in adolescents and young adults (Vincent et al. 1981, Vanamail et al. 1989, Rajasekariah et al. 1991) and (2) the parasite's nocturnal periodicity in the region (Rocha et al. 1991).

Although cluster sampling was used in selecting participants, the data analysis conducted assumed simple random sampling. As almost all selected schools in different city sectors contributed with similar proportions to the total sample (Table I), the cluster analysis was not considered to be necessary. This fact and the large sample investigated (10,857 students), probably did not affect the estimated confidence intervals.

The RO was choosen as a measure of association due to the the low prevalence of infection observed $(73 / 10,857=0.7$, Table I). Under these circumstances, the odds has the advantage of being insensitive to whether emphasis is placed on counting the events or the non-events in estimating risks.

The proportion of positive students $(0.7 \%)$ identified in this investigation suggests that, contrary to what was believed by the Ministry of Health (MS 1985), this parasitic infection had not been eradicated from Maceió. The city can be considered as an active transmission foci, once Culex mosquitoes have been found harboring natural $W$. bancrofti infection (Fontes et al. 1994). The fact that in only 10 out of 33 city sectors investigated autochthonous microfilaraemic students were identified, plus the finding that only in three city sectors the proportion of positive exceeded $1 \%$, indicate this infection to have a focal distribution in the city.

In the past, only one survey to detect $W$. bancrofti infection was carried out in Maceió (Deane et al. 1953). On that occasion 6,052 inhabitants were examined (6\% of the population) and 18 infected individuals were identified $(0.3 \%)$. Five out of the 11 city sectors investigated harbored the microfilariae carriers, indicating, at that time, a focal distribution. The majority of microfilarial infections (67\%) were found to be living in a city sector named Farol, contiguous to the three city sectors presenting higher proportion of positive in the present investigation (Fig.). This fact strongly suggests the current transmission foci to be an extension of the original foci described 45 years ago.

The proportion of positive participants identified in the current investigation was significantly greater $(\mathrm{p}<0.01)$ than the one reported in 1953. This increase can probably be linked to a marked growth in Maceió's urban population; this change was not followed by basic sanitation measures, as wastewater disposal and sewage systems, allowing the proliferation of the parasite's mosquito vector and, in consequence, an increase in the disease frequency. Only 27\% of Maceió's population is served by a sewage system. The existence of polluted and stagnant water around the housing, together with a high population density observed in the city sectors with greater proportion of positive students, were considered as the determinant factors in the maintenance and expansion of the original transmission foci.

In the earlier investigation, no data regarding the origin of the microfilariae carriers was collected. Because infected mosquitoes were captured in the area, it was assumed that transmission was occurring. In the present study, all but one of the identified $W$. bancrofti infection were considered to be autochthonous. Among the students not born in the region, time of residence in Maceió was strongly linked to the infection.

In relation to the sex distribution observed among positive students, the results are in accordance to reports from urban areas in India (Pani et al. 1991) and Nigeria (Udonsi 1988). It should be pointed out, however, that no significant difference between the proportion of infected males and females was observed in Indonesia (Dennis et al. 1976) and Haiti (Raccurt et al. 1988), similar to the results obtained in the 1953 survey conducted in Maceió (Deane et al. 1953). Reviewing the different susceptibility between the sexes to the $W$. bancrofti infection and the implications of maternal-child immunity Brabin (1990) showed that in 43 out of 53 investigations analyzed, males had a higher proportion of infection when compared to females. Although the results obtained in the present investigation also indicated a higher proportion of positives among male students, a definitive conclusion about the sex distribution of lymphatic filariasis in Maceió can only be reached when other age groups would be also investigated.

The results of this investigation, updating the knowledge of the current situation about this helminthic infection in this region, were used as baseline information for the implementation of a control program by the local Health Department. The program aimed to reduce and control the transmission rates and prevent the appearance of chronic clinical cases, who may present lesions that are, sometimes, irreversible.

\section{ACKNOWLEDGMENT}

To the examined students for their cooperation and to the academic trainees from Pathology Department of the Federal University of Alagoas for their dedicated assistance in field and laboratory work. To Prof. Geraldo Vergetti and Dr Gerusa Dreyer for their interest and encouragement; to George LLM Coelho for help with statistical analysis and José C Mauricio da Rocha Filho for the figure. 


\section{REFERENCES}

Brabin L 1990. Sex differentials in susceptibility to lymphatic filariasis and implications for maternal child immunity. Epidemiol Infect 105: 335-353.

Deane LM, Rosa D, Rachou RG, Martins JS, Costa A, Gomes HM, Carvalho ME 1953. A filariose bancroftiana em Maceió, Alagoas: resultado de um inquérito realizado em 1952. Rev Bras Malariol D Trop 8: 17-22.

Dennis DT, Partono F, Purmono, Atmosoedjono S, Saroso JS 1976. Timor filariasis: epidemiologic and clinical features in a defined community. Am J Trop Med Hyg 25: 797-802.

Dreyer G, Medeiros Z 1990. Filariose linfática: ainda um desafio. Ciência Hoje 12: 6-7.

Dreyer G, Medeiros Z, Beliz F, Vergetti G, Vergetti A, Café T, Fontes G 1991. Autochthonous Wuchereria bancrofti microfilaremia in the city of MaceióAlagoas-Brazil. Mem Inst Oswaldo Cruz 86: 495496.

Fontes G, Brito AC, Calheiros CML, Antunes CMF, Rocha EMM 1994. Situação atual da filariose bancroftiana na cidade de Maceió, Estado de Alagoas, Brasil. Cad Saúde Públ 10 (Supl. 2): 293300.

MS - Ministério da Saúde 1985. Controle das Endemias no Brasil (de 1979 a 1984), Superintendência de Campanhas de Saúde Pública, SUCAM, Brasília, DF, $154 \mathrm{pp}$.

Orihel TC 1985. Filariae, p. 171-191. In PC Beaver, RC Jung (eds), Animals Agents and Vectors of $\mathrm{Hu}$ man Disease, 5th ed., Lea \& Febiger, Philadelphia.

Ottesen EA, Ramachandran CP 1995. Lymphatic filariasis, infection and disease: control strategies. Parasitol Today 11: 129-131.

Pani SP, Balakrishnan N, Srividya A, Bundy DAP, Grenfell BT 1991. Clinical epidemiology of Bancroftian filariasis: the effect of age and gender. Trans R Soc Trop Med Hyg 85: 260-264.

Partono F, Idris KN 1977. Some factors influencing the loss of microfilariae from stained thick blood films. Southeast Asian J Trop Med Pub Hlth 8: 158-164. Raccurt CP, Lowrie RC, Katz JSP, Duverseau YT 1988.
Epidemiology of Wuchereria bancrofti in Leogane, Haiti. Trans R Soc Trop Med Hyg 82: 721-725.

Rachou RG 1957. Distribuição geográfica das filarioses humanas no Brasil. Rev Bras Malariol D Trop 9: 79-100.

Rachou RG 1960. Conceito e programa de profilaxia da filariose bancroftiana no Brasil. Rev Bras Malariol D Trop 12: 11-40.

Rajasekariah GR, Parab PB, Chandrashekar R, Deshpande L, Subrahmanyam D 1991. Pattern of Wuchereria bancrofti microfilaraemia in young and adolescent school children in Bassein, India, an endemic area for lymphatic filariasis. Ann Trop Med Parasitol 85: 663-665.

Rocha EMM, Fontes G, Vergetti G, Santos ACB, Fireman FAT, Dreyer G 1991. Periodicidade de microfilárias de Wuchereria bancrofti em filarióticos autóctones de Maceió - AL. Rev Inst Med Trop $S$ Paulo 33 (Supl. 8): 35.

Udonsi JK 1988. Bancroftian filariasis in the Igwun Basin, Nigeria. An epidemiological, parasitological and clinical study in relation to the transmission dynamics. Acta Trop 45: 171-179.

Vanamail P, Subramanian S, Das PK, Pani SP, Rajagopalan PK, Bundy DAP, Grenfell BT 1989. Estimation of age-especific rates of acquisition and loss of Wuchereria bancrofti infection. Trans $R$ Soc Trop Med Hyg 83: 689-693.

Vincent AL, Gomez MV, Gonzalvo A, Naya J, Sodeman Jr WA 1981. Filariasis in the Dominican Republic. Am J Trop Med Hyg 30: 739-741.

WHO - World Health Organization 1987. Control of Lymphatic Filariasis: A Manual for Health Personnel, WHO Geneva, 89 pp.

WHO - World Health Organization 1992. Lymphatic Filariasis: the Disease and its Control, Fifth report of the WHO Expert Committee on Filariasis (WHO Technical Report Series 821), WHO Geneva, 75 pp.

WHO - World Health Organization 1994. Lymphatic Filariasis Infection \& Disease: Control Strategies, Report of a consultative meeting held at the Universiti Sains Malaysia, Penang, Malaysia, WHO, TDR/CTD/FIL/PENANG/94.1, 30 pp. 